\title{
Análise de tendência de temperatura e precipitação e cenários de mudanças climáticas para Pelotas (RS)
}

A cidade de Pelotas, localizada no extremo sul do estado do Rio Grande do Sul, sofre com a grande quantidade de chuvas em certas épocas do ano. Desta forma, as variáveis meteorológicas de temperatura e precipitação são importantes para os estudos dos impactos das mudanças climáticas, pois afetam a disponibilidade dos recursos ambientais. Esse estudo teve como objetivo detectar alterações nos padrões de temperatura e precipitação como indicativo de mudanças climáticas para a região de Pelotas (RS) ao longo do século XXI (2006-2099), comparando com o clima no período atual (1961- 2005), por meio de projeç̃̃es destas variáveis geradas por diferentes modelos climáticos com base nos cenários climáticos RCP 4.5 e RCP 8.5 do quinto relatório do IPCC (AR5). As projeções indicam um aumento de temperatura média anual de pelo menos $3^{\circ} \mathrm{C}$ até o final do século para o cenário $\mathrm{RCP} 4.5$ e um aumento de até $4,5^{\circ} \mathrm{C}$ para o relatório do IPCC (AR5). As projeções indicam um aumento de temperatura média anual de pelo menos $3^{\circ} \mathrm{C}$ até o final do século para o cenário $\mathrm{RCP} 4.5 \mathrm{e}$ um aumento de até $4,5^{\circ} \mathrm{C}$ para $\mathrm{O}$
cenário RCP 8.5, bem como um aumento expressivo na precipitação anual acumulada. Em relação à agricultura, os ciclos mensais de temperatura e precipitação demonstram que os meses das culturas de verão serão menos afetados pelo aumento destas variáveis; porém, os possíveis extremos aparecerão no aumento da precipitação nos meses de outubro e novembro, início dos cultivos. Pode-se destacar que as anomalias de temperatura indicaram um aumento expressivo principalmente para o final do século. Ressaltando então que para o cenário RCP 4.5 , considerado o cenário otimista neste trabalho, o modelo MIROC5 que apresentou menores valores de anomalia positiva, indica um aumento médio na temperatura de $0,5^{\circ} \mathrm{C}$ para $\mathrm{F} 1$ (20062037), enquanto os outros modelos indicam pelo menos $1^{\circ} \mathrm{C}$ de aumento.

Palavras-chave: Mudanças climáticas; Modelos climáticos; RS; Pelotas; Modelo ETA.

\section{Temperature and rainfall trend analysis and climate change scenarios for Pelotas (RS)}

\begin{abstract}
The city of Pelotas, located in the extreme south of the state of Rio Grande do Sul, suffers from heavy rainfall at certain times of the year. Thus, temperature and precipitation meteorological variables are important for studies of climate change impacts, as they affect the availability of environmental resources. This study aimed to detect changes in temperature and precipitation patterns as indicative of climate change for the Pelotas (RS) region during the 21st century (2006-2099), compared with the climate in the current period (1961-2005), by projecting these variables generated by different climate models based on the RCP 4.5 and RCP 8.5 climate scenarios of the IPCC's fifth report (AR5). Projections indicate an average annual temperature increase of at least $3^{\circ} \mathrm{C}$ by the end of the century for the RCP 4.5 scenario and an increase of up to $4.5^{\circ} \mathrm{C}$ for the RCP 8.5 scenario, as well as a significant increase in accumulated annual precipitation. Regarding agriculture, the monthly temperature and precipitation cycles show that summer crop months will be less affected by the increase of these variables; However, the possible extremes will appear in the increase of precipitation in the months of October and November, beginning of the crops. It should be noted that temperature anomalies indicated a significant increase mainly towards the end of the century. Noting then that for the RCP 4.5 scenario, considered the optimistic scenario in this paper, the MIROC5 model that presented lower positive anomaly values, indicates an average temperature increase of $0.5^{\circ} \mathrm{C}$ for $\mathrm{F} 1$ (2006-2037), while the others models indicate at least $1^{\circ} \mathrm{C}$ increase.
\end{abstract}

Keywords: Climate changes; Climate models; LOL; Pellets; ETA model.

Topic: Engenharia Ambiental

Reviewed anonymously in the process of blind peer
Received: 05/10/2018

Approved: 05/11/2018
Ritielle Rodrigues Anjos (iD

Universidade Federal de Pelotas, Brasil

http://lattes.cnpq.br/3750290452783012

http://orcid.org/0000-0002-9796-1048

ritielleanjos@hotmail.com

Tirzah Moreira Siqueira (iD

Universidade Federal de Pelotas, Brasil

http://lattes.cnpq.br/8413080701996952

http://orcid.org/0000-0002-1686-5282

tirzahmelo@hotmail.com

Viliam Cardoso da Silveira

Universidade Federal de Pelotas, Brasil

http://lattes.cnpq.br/1723649311410460

http://orcid.org/0000-0001-7438-5802

viliamcardoso2@gmail.com

\author{
Diuliana Leandro \\ Universidade Federal de Pelotas, Brasil \\ http://lattes.cnpq.br/3076528365846421 \\ http://orcid.org/0000-0002-8092-5550 \\ diuliana.leandro@gmail.com \\ Luciara Bilhalva Corrêa (iD) \\ Universidade Federal de Pelotas, Brasil \\ http://lattes.cnpq.br/0976948866231388 \\ http://orcid.org/0000-0002-1686-5282 \\ luciarabc@gmail.com \\ Daniela Buske (iD \\ Universidade Federal de Pelotas, Brasil \\ http://lattes.cnpq.br/3894096111082082 \\ http://orcid.org/0000-0002-4573-9787 \\ danielabuske@gmail.com
}

\section{Referencing this:}

ANJOS, R. R.; SIQUEIRA, T. M.; SILVEIRA, V. C.; LEANDRO, D.; CORRÊA, L. B.; BUSKE, D.; WEYMAR, G. J.. Análise de tendência de temperatura e precipitação e cenários de mudanças climáticas para Pelotas (RS). Revista Ibero-Americana de Ciências Ambientais, v.9, n.8, p.93-108, 2018. DOI: http://doi.org/10.6008/CBPC2179-6858.2018.008.0009

DOI: 10.6008/CBPC2179-6858.2018.008.0009 


\section{INTRODUÇÃO}

Diversas pesquisas realizadas desde o início do século XXI têm mostrado fortes indicadores da ocorrência de mudanças climáticas, não somente relacionadas à temperatura média, mas também aos extremos climáticos em escalas global e regional. Aumento na frequência de noites quentes, ondas de calor, precipitações pluviais diárias mais intensas, enchentes e secas pronunciadas têm sido observada em diversas partes do planeta, o que tem resultado em grandes impactos econômicos e sociais. Por outro lado, a amplitude térmica diária, ondas de frio e dias de geadas severas estão diminuindo significativamente (ASADIEH et al., 2015; HANSEN et al., 2010; IPCC, 2007, 2013).

Muitos países estão vulneráveis às alterações climáticas, devido ao aumento da população humana, escassez de água, degradação da terra e insegurança alimentar. No Brasil, algumas regiões poderão ter seus níveis de temperatura e de chuva modificados com o aquecimento global. Com a mudança dos padrões anuais de chuva, ou mesmo onde não houver alteração do total anual, deverá ocorrer intensificações de eventos severos. Marengo et al. (2008), ao estudar as temperaturas máximas e mínimas no Sul do Brasil de 1960 a 2002, encontrou um aquecimento sistemático da região, detectando tendências positivas na temperatura máxima e mínima em níveis anual e sazonal. A amplitude térmica indicou tendências negativas fortes nesse período, sugerindo que as alterações na temperatura mínima foram mais intensas do que nas máximas, especialmente no verão.

No estado do Rio Grande do Sul, sul do Brasil, destacam-se as tendências de aumento da temperatura mínima e de aumento do número de noites quentes, principalmente no outono e no verão. Coerente com esta tendência, Steinmetz et al. (2007) demostrou que, para a região de Pelotas (RS), a temperatura mínima aumentou $1,1^{\circ} \mathrm{C}$ no período $1893-2006$ e $1,8^{\circ} \mathrm{C}$ no período $1951-2006$.

O Painel Intergovernamental sobre Mudanças climáticas (IPCC) é um fórum destinado a tratar assuntos sobre as mudanças climáticas que foi criado pela Organização Meteorológica Mundial (OMM) e pelo Programa das Nações Unidas para o Meio Ambiente (PNUMA). Desde então, vem divulgando relatórios científicos, integrando resultados de pesquisas realizadas globalmente, que tem demonstrado o aquecimento do sistema climático do planeta. Conhecido como 5o Relatório de Avaliação ou AR5, o último relatório foi lançado em 2014, e quando equiparado aos anteriores (AR4 e AR3), este teve uma maior participação de países em desenvolvimento em sua concepção e um número significativamente maior de trabalhos científicos analisados (NOBRE et al., 2017).

Neste contexto, este trabalho buscou detectar tendências de longo período no padrão de precipitação e de temperatura na região de Pelotas (RS), onde o clima é controlado, principalmente, pela atuação das massas Polar e Tropical do Atlântico, com verões quentes $\left(22,9^{\circ} \mathrm{C}\right.$ em média) e invernos frescos (13,2 ${ }^{\circ} \mathrm{C}$ em média), como indicam as normais climatológicas da Estação Agroclimatológica (1971 - 2000) de Pelotas $\left(31^{\circ} 52^{\prime} \mathrm{S}, 52^{\circ} 21^{\prime} \mathrm{W}, 13,2 \mathrm{~m}\right)$. Foram consideradas as séries do período atual de precipitação e temperatura, bem como cenários do clima futuro, segundo projeções geradas por três modelos de circulação geral regionalizados pelo modelo ETA. 
O objetivo deste trabalho é detectar alterações nos padrões de temperatura e precipitação como indicativo de mudanças climáticas para a região de Pelotas (RS) ao longo do século XXI (2006-2099), comparando com o clima no período atual (1961-2005), por meio de projeções destas variáveis geradas por diferentes modelos climáticos com base nos cenários climáticos RCP 4.5 e RCP 8.5 do Quinto Relatório de Avaliação (AR5), do Painel Intergovernamental sobre Mudanças Climáticas.

\section{REVISÃO TEÓRICA}

\section{Mudanças climáticas}

A sociedade tem debatido frequentemente sobre as mudanças climáticas e suas implicações no meio em que vivemos. Essa preocupação está relacionada aos impactos das alterações climáticas sobre as diversas atividades humanas que podem impactar o meio ambiente, principalmente, os efeitos dos extremos climáticos que se tornam mais constantes (SOUZA et al., 2009).

Os padrões de precipitação são diretamente afetados pela mudança na temperatura média global, que está fortemente relacionada ao aumento de gases na atmosfera, tais como: dióxido de carbono, metano e óxido nitroso (IPCC, 2013). Aumento nos volumes totais de chuvas, assim como suas intensidades, podem causar fortes impactos nos sistemas de drenagem urbana.

No seu Quinto Relatório de Avaliação (AR5) de 2014, o IPCC usou os novos cenários RCPs (Representative Concentration Pathways) (MOSS et al., 2010). Estes são os chamados 'Caminhos Representativos de Concentração', e cada um dos quatro cenários considera o histórico evolutivo de diversos motivos, como a forçante radiativa na atmosfera, emissão de gases, concentração de gases de efeito estufa, bem como informações de tipo de cobertura terrestre para as projeções. De acordo com as concentrações de gases de efeito estufa e aerossóis, obtém-se o quanto de energia ficou armazenada no sistema terrestre, sendo assim o balanço de radiação é calculado pela razão entre a quantidade de radiação solar que entra e que sai da Terra pelos cenários (RCPs).

\section{Modelos de Circulação Geral}

Os Modelos de Circulação Geral são um dos instrumentos mais avançados disponíveis para estimar a resposta do sistema climático global ao aumento dos níveis de gases de efeito estufa (IPCC, 2007). Esses modelos são capazes de modelar numericamente os processos físicos da atmosfera, oceano, criosfera e superfície terrestre. Há um grande número de MCGs, cujos resultados são fornecidos por vários centros de pesquisa em todo o mundo, e que podem variar em precisão, dependendo de sua resolução de grade espacial e outros fatores. Eles são capazes de projetar mudanças na atmosfera terrestre causada pelos elementos causadores do aquecimento global, especialmente os gases de efeito estufa (SRIVASTAV et al., 2015).

O Instituto Nacional de Ciência e Tecnologia (INCT) para Mudanças Climáticas iniciou, em 2009, o desenvolvimento de cenários climáticos futuros até 2100 , aplicando técnicas de regionalização (downscaling dinâmico), com modelos climáticos regionais de alta resolução $(20,40 \mathrm{~km}$ de resolução espacial) forçados a 
partir das projeções climáticas de modelos climáticos globais do Reino Unido, Japão e, recentemente, do Modelo Brasileiro do Sistema Terrestre (BESM), usando o modelo regional ETA utilizado pelo INPE (Instituto Nacional de Pesquisas Espaciais).

Dezenas de estudos baseados nesse método de regionalização (downscaling) de cenários globais e nas análises das projeções de mudanças climáticas do IPCC para a América do Sul têm permitido identificar cenários possíveis de mudanças climáticas para as próximas décadas, até 2100 (NOBRE et al., 2017). Em 2014, os novos cenários foram derivados usando o modelo regional ETA com $20 \mathrm{~km}$ de resolução espacial. Desses estudos, 23 avaliam projeções de clima até 2100 , geradas pelo modelo ETA para América do Sul, com ênfase nas grandes bacias que fazem parte o sistema hidrelétrico brasileiro.

O modelo ETA tem sido utilizado pelo INPE para produzir previsões em alta resolução, para previsões de tempo (CHOU, 1996; SELUCHI et al., 2003; SELUCHI et al., 2003; VIEIRA et al., 2015; SIQUEIRA et al., 2016), clima sazonal (CHOU et al., 2005; PILOTTO et al., 2012; RESENDE et al., 2015) e clima subsazonal (CHOU et al., 2005). O INPE tem usado os modelos globais do Painel Intergovernamental sobre Mudanças Climáticas (IPCC) do Quinto Relatório de avaliação (AR5), modelos do Japão (MIROC5) e do Reino Unido (HadGEM2-ES) para rodar o ETA $20 \mathrm{~km}$ para os cenários RCP 4.5 (emissões medias) e RCP 8.5 (altas emissões), até 2100.

\section{Os impactos das mudanças climáticas sobre o meio ambiente}

O impacto do aumento da temperatura devido às mudanças climáticas tem sido uma preocupação mundial para várias áreas de pesquisa (AKBARI et al., 2016; SCHNEIDEMESSER et al., 2015). Entre os vários impactos potenciais da mudança climática, os que são de especial preocupação são os recursos essenciais para o bem-estar humano, como a disponibilidade de água e a agricultura, com impactos diretos nas atividades econômicas e na segurança alimentar.

A agricultura está entre as atividades humanas mais vulneráveis às mudanças climáticas (RAMIREZVILLEGAS et al., 2012; BECK, 2013). Os impactos estão relacionados ao encurtamento do período de crescimento e floração, juntamente com a redução do número e tamanho dos grãos, bem como o rendimento total (CRAUFURD et al., 2009; ROSE et al., 2016). Consequentemente, em muitos países, a produtividade agrícola das culturas é afetada de alguma forma pelo aumento da temperatura (LOBELL et al., 2011), e muitos modelos previram que o rendimento das culturas continuarão a diminuir em cenários climáticos futuros (KANG et al., 2009; ASSENG et al., 2015). Diversas pesquisas têm investigado o impacto das mudanças climáticas globais na biologia e produtividade de espécies de plantas agrícolas (BECK, 2013; RANJITKAR et al., 2016).

Pesquisas recentes analisaram os possíveis efeitos das mudanças ambientais climáticas sobre a saúde, com o agravamento da incidência de problemas de saúde existentes, se mantidos os seus padrões socioepidemiológicos (GONÇALVES, 2016). A dispersão espacial de algumas doenças para novas áreas receptivas e vulneráveis; e a emergência de novas doenças, principalmente em relação as arboviroses, como Zika, dengue e Chikungunya (BARCELLOS et al., 2014). 
No estado do Rio Grande do Sul, de forma geral, encontrou-se tendências menores de aumento para as temperaturas máximas do que para as mínimas e também tendências negativas (COSTA et al., 2010). Costa et al. (2010) verificou áreas relativamente grandes com tendências negativas, como no sudoeste do estado, para os quatro trimestres do ano, em especial no outono e, na região serrana (Bento Gonçalves), também para os quatro trimestres. No entanto, no litoral, principalmente ao norte de Pelotas, bem como na região de São Luiz Gonzaga (noroeste) e de Encruzilhada do Sul (sudeste), as tendências foram positivas, principalmente na primavera e verão. Coerente com esta tendência, Steinmetz et al. (2007) mostrou, para a região de Pelotas (RS), que a temperatura mínima aumentou $1,1^{\circ} \mathrm{C}$ no período $1893-2006$ e $1,8^{\circ} \mathrm{C}$ no período 1951-2006.

\section{METODOLOGIA}

\section{Área de estudo}

O município de Pelotas localiza-se no sul do estado do Rio Grande do Sul, na latitude 314619” S e longitude $52020^{\prime} 33^{\prime \prime} \mathrm{W}$. Ocupa uma área total de $1.610,084 \mathrm{~km}^{2} \mathrm{com}$ topografia predominantemente plana e de altitudes baixas. A altitude média é de 7 metros acima do nível do mar e a cidade está localizada a cerca de $60 \mathrm{~km}$ do Oceano Atlântico, e a $250 \mathrm{~km}$ sul da capital do estado, Porto Alegre, com população estimada em 344.385 habitantes (IBGE, 2017).

Pelotas possui em seu território uma parte da lagoa dos Patos, a praia do laranjal, que apesar de popularmente ser conhecida como uma lagoa, é considerada uma laguna por se comunicar com o mar. Os solos predominantes na região são o neossolo litorâneo eutrófico, vertissolo e chernossolo, sendo este último ideal para plantação de arroz, e apresenta razoáveis teores de matéria orgânica (CABRERA et al., 2008). A área de estudo segue identificada na figura 1.

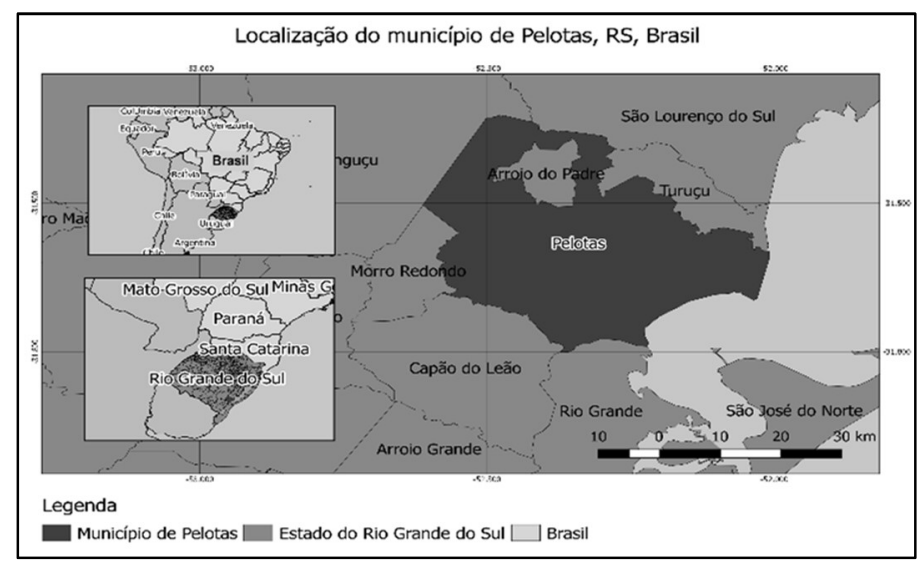

Figura 1: Mapa do município de Pelotas.

\section{Dados meteorológicos e modelos climáticos}

Os dados meteorológicos usados na pesquisa foram temperatura $\left({ }^{\circ} \mathrm{C}\right)$ e precipitação anual acumulada $(\mathrm{mm})$, que foram retiradas da plataforma PROJETA, Projeções de Mudança do Clima para a América do Sul Regionalizadas pelo modelo ETA. Os modelos de circulação globais utilizados nesse estudo 
são o HADGEM2-ES, o MIROC5 e o CANESM2. Esses modelos sofreram uma regionalização (downscaling) pelo modelo ETA.

As projeções de todos os modelos climáticos usados foram para a localização $31^{\circ} 77^{\prime} 05^{\prime \prime} \mathrm{S} 52^{\circ} 32^{\prime}$ 49" W. O único diferencial entre os modelos em relação a sua localização é a resolução, essas projeções incluem precipitação e temperatura para o período base ou de comparação (1961-2005), curto prazo (20062037), médio prazo (2038-2068) e longo prazo (2069-2099). Períodos futuros serão representados neste trabalho pelas siglas F1, F2 e F3.

\section{Análise de tendência}

O Teste de Mann-Kendall foi empregado para identificar se as séries de precipitação e temperatura possuem uma tendência temporal de alteração estatisticamente significativa. Back (2001) e Moraes et al. (1995) descrevem o método considerando uma série temporal de $X_{i}$ de $\mathrm{N}$ termos $(1 \leq \mathrm{i} \leq \mathrm{N})$. $O$ teste consiste na soma $t_{n}$ do número de termos $m_{i}$ da série, relativo ao valor $X_{i}$, cujos termos precedentes $(\mathrm{j}<\mathrm{i})$ são inferiores ao mesmo $\left(X_{j}>X_{i}\right)$. Isto é: $\mathrm{t}_{\mathrm{n}}=\sum_{\mathrm{i}=1}^{\mathrm{n}} \mathrm{m}_{\mathrm{i}}$.

Para séries com grande número de termos $(\mathrm{N})$, sob a hipótese nula $\left(H_{0}\right)$ de ausência de tendência, $t_{n}$ apresentará uma distribuição normal com média $\left(\mathrm{E}\left(t_{n}\right)\right)$ e variância $\left(\operatorname{Var}\left(t_{n}\right)\right): E\left(\mathrm{t}_{\mathrm{n}}\right)=\frac{\mathrm{N}(\mathrm{N}-1)}{4}$; e $\operatorname{Var}\left(\mathrm{t}_{\mathrm{n}}\right)=\frac{\mathrm{N}(\mathrm{N}-1)(2 \mathrm{~N}+5)}{72}$. Testando a significância estatística de $t_{n}$ para a hipótese $H_{0}$ usando um teste bilateral, esta pode ser rejeitada para grandes valores da estatística $u(t)$, pela seguinte equação: $u(t)=$ $\frac{\left(t_{n-E\left(t_{n}\right)}\right)}{\sqrt{\operatorname{Var}\left(t_{n}\right)}}$. O valor da probabilidade $\alpha 1$ é calculado por meio de uma tabela da normal reduzida, tal que $\alpha 1=$ $\operatorname{prob}(|\mathrm{u}|)>|\mathrm{u}(\mathrm{t})|$.

\section{Análise Sazonal}

Uma análise inicial das projeções de temperatura e de precipitação foi conduzida tomando-se a média dos valores mensais destas variáveis dadas por todos os modelos em uma localização, e então calculando-se as anomalias comparadas com o período base (1961-2005). As anomalias se referem às diferenças entre cada período futuro de 30 anos, curto prazo (2006-2037), médio prazo (2038-2068) e longo prazo (2069-2099), e o período base de 45 anos (1961-2005).

\section{RESULTADOS}

\section{Análise das séries anuais de temperatura e precipitação}

Uma breve análise dos dados meteorológicos anuais é apresentada nas tabelas 1 e 2, onde os resultados das médias de cada modelo são apresentados de acordo com o período (F1, F2 ou F3) para os cenários RCP 4.5 e RCP 8.5. Foram calculadas as anomalias considerando o período base (1961-2005). Analisando os gráficos de anomalias de temperatura dos cenários RCP 4.5 e RCP 8.5 (Figura 2) é possível observar que as projeções indicam um aumento da temperatura, quando comparadas com o período base. 
As maiores anomalias são previstas para o final do século. De acordo com a Figura 3 pode-se identificar que o RCP 8.5 para F3 (2069-2099) possui dois modelos que indicam um aumento de mais de $3,5^{\circ} \mathrm{C}$ na temperatura. No RCP 4.5 pode ocorrer um aumento de pelo menos $2^{\circ} \mathrm{C}$, apresentado na figura 2 , como previsto pelos mesmos modelos que indicam maior anomalia para o RCP 8.5.

Tabela 1: Médias de Temperatura e Precipitação para o RCP 4.5.

\begin{tabular}{|c|c|c|c|c|}
\hline \multirow[t]{2}{*}{ Variável } & \multirow[t]{2}{*}{ Período } & \multicolumn{3}{|c|}{ PELOTAS } \\
\hline & & CANESM2 & MIROC5 & HADGEM2-ES \\
\hline \multirow[t]{4}{*}{$\mathrm{T}\left({ }^{\circ} \mathrm{C}\right)$} & Histórico & 18.01 & 16.96 & 18.39 \\
\hline & F1 (2006-2037) & 19.10 & 17.34 & 19.65 \\
\hline & F2 (2038-2068) & 19.91 & 17.71 & 20.17 \\
\hline & F3 (2069-2099) & 20.41 & 17.99 & 20.60 \\
\hline \multirow[t]{4}{*}{$P(\mathrm{~mm})$} & Histórico & 1790.39 & 1132.13 & 1520.48 \\
\hline & F1 (2006-2037) & 1897.38 & 1141.03 & 1555.52 \\
\hline & F2 (2038-2068) & 1959.51 & 1178.94 & 1644.49 \\
\hline & F3 (2069-2099) & 1972.62 & 1244.47 & 1705.70 \\
\hline
\end{tabular}

Tabela 2: Médias de Temperatura e Precipitação para o RCP 8.5.

\begin{tabular}{|c|c|c|c|c|}
\hline Variável & Período & \multicolumn{3}{|c|}{ PELOTAS } \\
\cline { 2 - 4 } & & CANESM2 & MIROC5 & HADGEM2-ES \\
\hline T $\left({ }^{\circ} \mathbf{C}\right)$ & Histórico & 18.01 & 16.96 & 18.39 \\
& F1 (2006-2037) & 19.13 & 17.56 & 19.79 \\
& F2 (2038-2068) & 20.31 & 18.13 & 20.46 \\
& F3 (2069-2099) & 21.57 & 18.91 & 1520.48 \\
\hline P (mm) & Histórico & 1790.39 & 1132.13 & 1500.49 \\
& F1 (2006-2037) & 1904.66 & 1176.25 & 1690.41 \\
& F2 (2038-2068) & 2075.77 & 1229.56 & 1792.18 \\
\hline
\end{tabular}
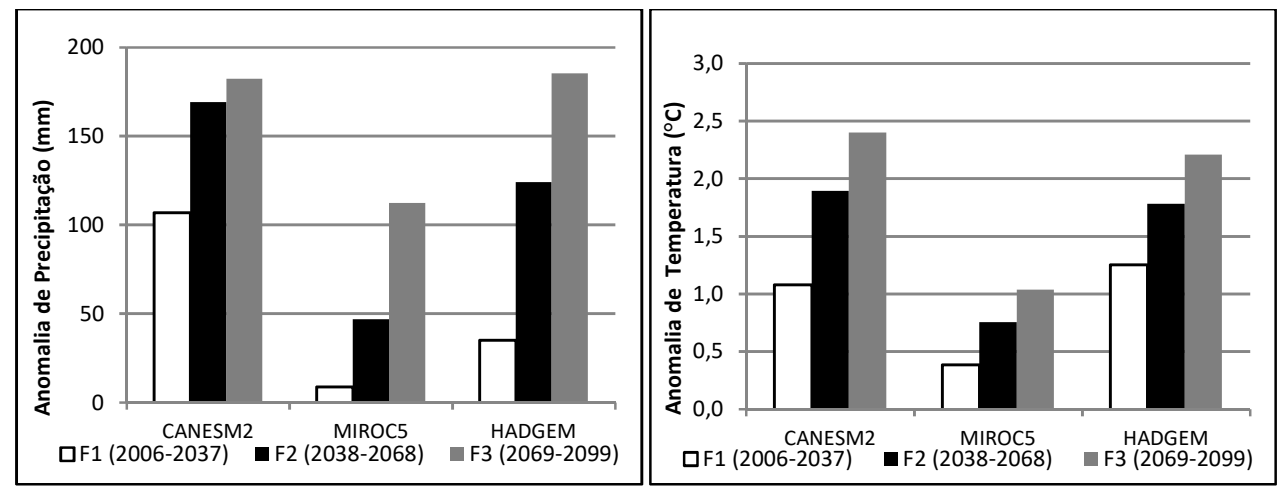

Figura 2: Anomalias de temperatura e precipitação para o cenário RCP 4.5, para Pelotas (RS).
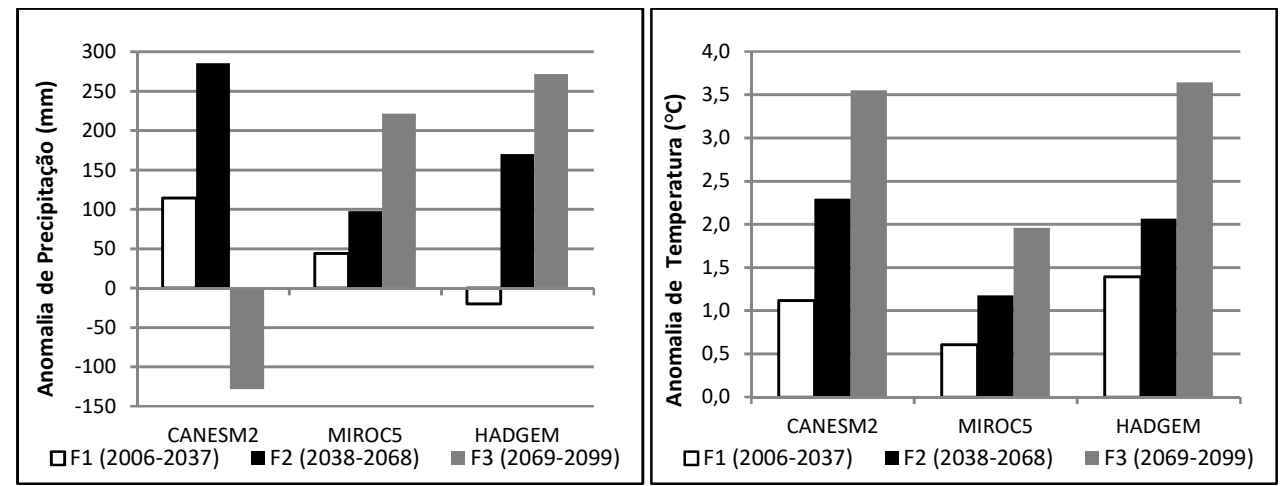

Figura 3: Anomalias de temperatura e precipitação para o cenário RCP 8.5, para Pelotas (RS).

Para a precipitação dada pelo RCP 4.5 os modelos indicam um aumento, onde as maiores anomalias se encontram no final do século (2069-2099), podendo passar de 150mm para o modelo CANESM2 e 
HADGEM2-ES. Para o RCP 8.5 houve uma divergência entre as anomalias dos modelos, o MIROC5 e HADGEM2-ES apresentam um aumento na precipitação, enquanto o modelo CANESM2 mostra uma diminuição de até125 mm. As projeções de temperatura apresentaram aumento nos três períodos projetados (F1, F2 e F3), reafirmando a perspectiva dos padrões de temperatura futuros.

\section{Análise de tendência das séries de temperatura e precipitação}

O teste de Mann-Kendall permitiu detectar tendências estatisticamente significativas e foi utilizado nesse estudo para identificar se existe tendência ou não a um nível de significância nos modelos. O p-valor indica o erro assumido ao se rejeitar a hipótese nula, ou seja, o erro em assumir que há tendência de aumento ou diminuição da variável na série(s) analisada(s) ao longo do século, para um determinado modelo. No caso, considerou-se o nível de significância do teste de 0,05 ; se o resultado obtido for menor que esse valor, podese, então, rejeitar a hipótese de não haver tendência, ou seja, há tendência. A hipótese nula é rejeitada quando existe uma tendência significativa na série temporal. Observe-se que sempre que o valor-p foi alto na Tabela 3, a hipótese nula não é rejeitada (valor 0 na tabela indica que a hipótese nula foi aceita; valor 1 indica que a hipótese nula foi rejeitada e assumiu-se a hipótese alternativa).

De acordo com a tabela 3, nota-se que os resultados de tendência estão condizentes, onde na variável temperatura apenas o modelo MIROC5 para a projeção do período histórico não indica tendência, os demais modelos indicam tendência de aumento de temperatura. Para a precipitação na projeção no período histórico apenas o modelo MIROC5 mostra tendência, enquanto que nas projeções para o RCP 4.5 não se pode assumir a hipótese de tendência em nenhum modelo, e no RCP 8.5 todos os modelos indicam tendência, sendo que o modelo CANESM2 indica uma tendência de diminuição enquanto os modelos MIROC5 e HADGEM2-ES indicam aumento na temperatura.

Tabela 3: Aplicação do teste Mann Kendall para as variáveis de precipitação e temperatura.

\begin{tabular}{|c|c|c|c|}
\hline \multicolumn{4}{|c|}{ Precipitação } \\
\hline & CANESM2 & MIROC5 & HADGEM2-ES \\
\hline Histórico & 0 & 1 & 0 \\
\hline p-valor & 0.4396 & 0.0034 & 0.2776 \\
\hline RCP 4.5 & 0 & 0 & 0 \\
\hline p-valor & 0.1296 & 0.2371 & 0.0945 \\
\hline RCP 8.5 & 1 & 1 & 1 \\
\hline p-valor & 0.0263 & 0.0009 & $<0.0001$ \\
\hline \multicolumn{4}{|c|}{ Temperatura } \\
\hline & CANESM2 & MIROC5 & HADGEM2-ES \\
\hline Histórico & 1 & 0 & 1 \\
\hline p-valor & 0.0014 & 0.3630 & 0.0471 \\
\hline RCP 4.5 & 1 & 1 & 1 \\
\hline p-valor & $<0.0001$ & $<0.0001$ & $<0.0001$ \\
\hline RCP 8.5 & 1 & 1 & 1 \\
\hline$p$-valor & $<0.0001$ & $<0.0001$ & $<0.0001$ \\
\hline
\end{tabular}

\section{Análise de sazonalidade de temperatura e precipitação}

Inicialmente uma análise das projeções das variáveis de temperatura e precipitação foi conduzida tomando-se as médias dos valores mensais, e calculando-se então as anomalias com relação ao período base 
(1961-2005) (figura 4). A anomalia se refere à diferença entre cada período futuro com o período base representado por uma série de 45 anos.

Pode ser observado, na figura 4, que, para o cenário RCP 4.5, os futuros F1, F2 e F3 indicaram um aumento de precipitação para o início da primavera e início de outono. Pode ser observado na Figura 5 que para a projeção RCP 4.5 os maiores aumentos de temperatura são esperados para o outono e início de inverno, de abril a junho, e no início da primavera surge um aumento novamente, entre outubro e novembro. Apenas o modelo MIROC5 para F1 (2006-2037) nos meses de maio para projeção 4.5 e junho para projeção 8.5 , apresentou anomalia negativa, $-0,2^{\circ} \mathrm{C}$ e $-0,5^{\circ} \mathrm{C}$, respectivamente.

Para o cenário RCP 8.5 da variável precipitação, os meses de março, abril e maio na maioria dos modelos apresentaram anomalia positiva. As maiores anomalias para a precipitação de F1 (2006-2037) na maioria dos modelos se encontra em junho, em F2 (2038-2068) se encontram em março e maio e em F3 as maiores anomalias se encontram em maio e novembro.

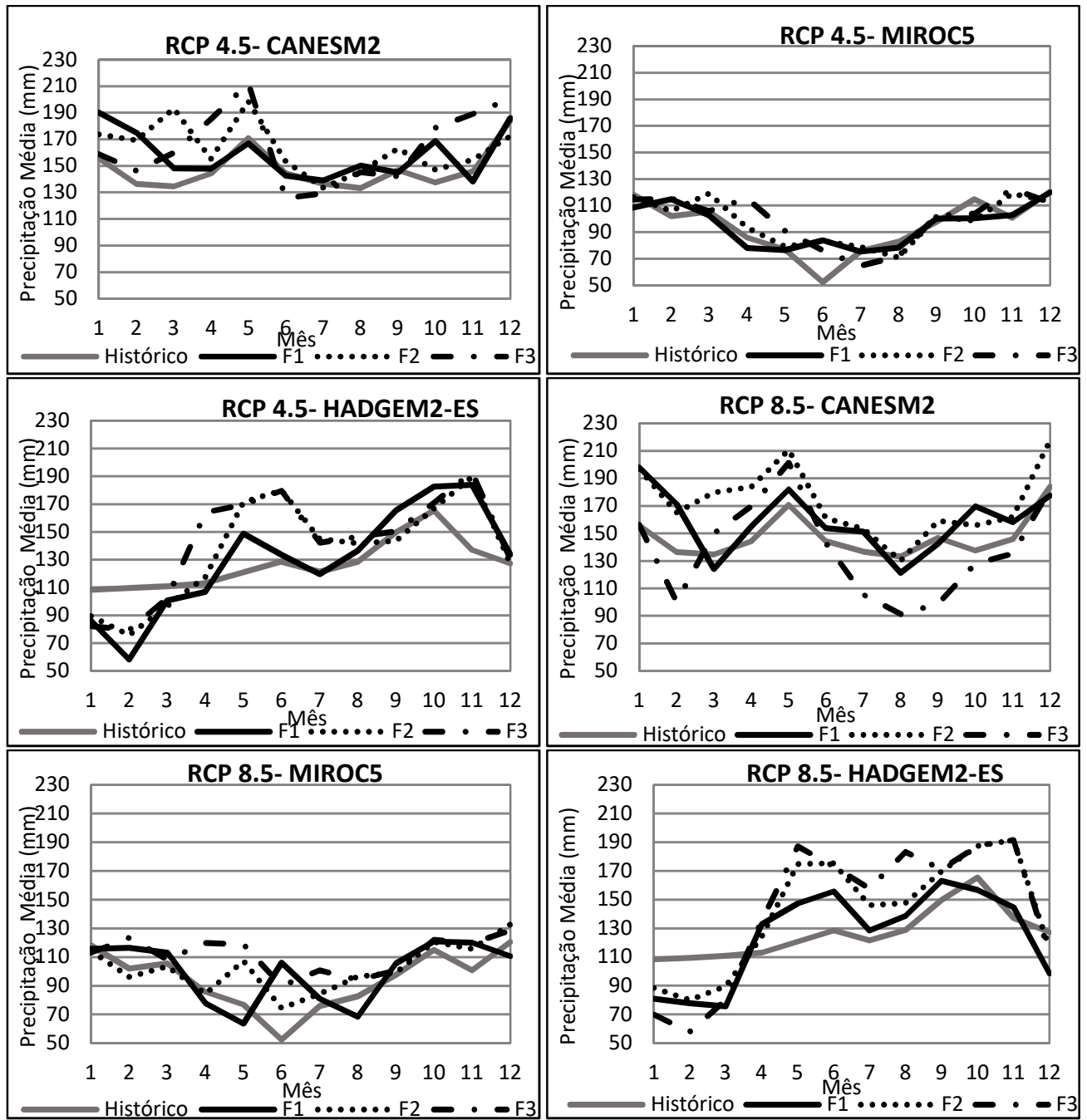

Figura 4: Médias mensais das projeções de precipitação $(\mathrm{mm})$ para os MCGs regionalizados pelo modelo ETA para Pelotas (RS).

Para a temperatura (figura 5) se observa um aumento para abril, maio e junho, no outono e início de inverno. Para anomalias positivas de temperatura foram registradas em F1 para diferentes meses, cada 
modelo apresentou um mês diferente, F2 para os três primeiros meses e dezembro, F3 todos os modelos demonstram aumento para os seis meses iniciais do ano.

Ao analisar os gráficos de anomalias (figura 6), notou-se que para o cenário RCP 4.5 o modelo HADGEM2-ES indica para fevereiro uma diminuição da precipitação em seus três cenários futuros, para F1 (2006-2037) indica -51,3 mm, para F2 (2038-2068) -33,7 mm e para F3 (2039-2099) -30,1mm, esse mesmo modelo indicou para F2 e F3 um aumento de até $50 \mathrm{~mm}$ para os meses de maio e junho, também apontou uma anomalia positiva de mais de $40 \mathrm{~mm}$ para F1, F2 e F3 em novembro.
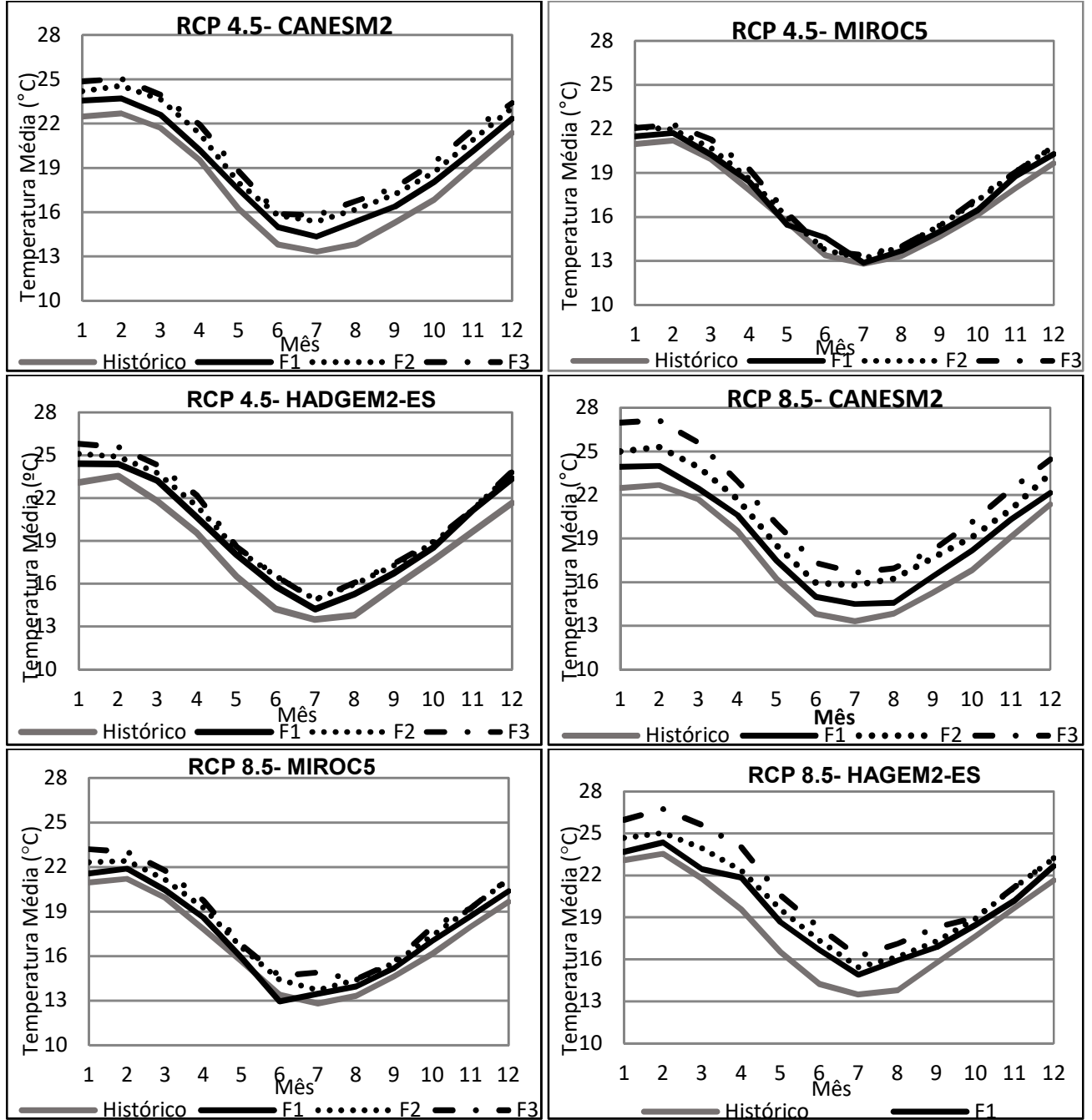

Figura 5: Médias mensais das projeções de temperatura $\left({ }^{\circ} \mathrm{C}\right)$ para os MCGs regionalizados pelo modelo ETA para Pelotas (RS).

O modelo MIROC5 indica aumento de precipitação para F2 de $30 \mathrm{~mm}$ para abril e junho e de mais de 20mm para F3. Para a projeção de RCP 8.5 o modelo HADGEM2-ES indicou para os meses de maio, junho e novembro para F2 e F3 pelo menos 50mm de aumento na precipitação, sendo que o F3 do mês de maio pode chegar a 66,2 mm de aumento. O modelo MIROC5 para F1 em junho indicou um aumento de mais de $50 \mathrm{~mm}$, e em maio para F2 e F3 indicaram um aumento de pelo menos $30 \mathrm{~mm}$. 


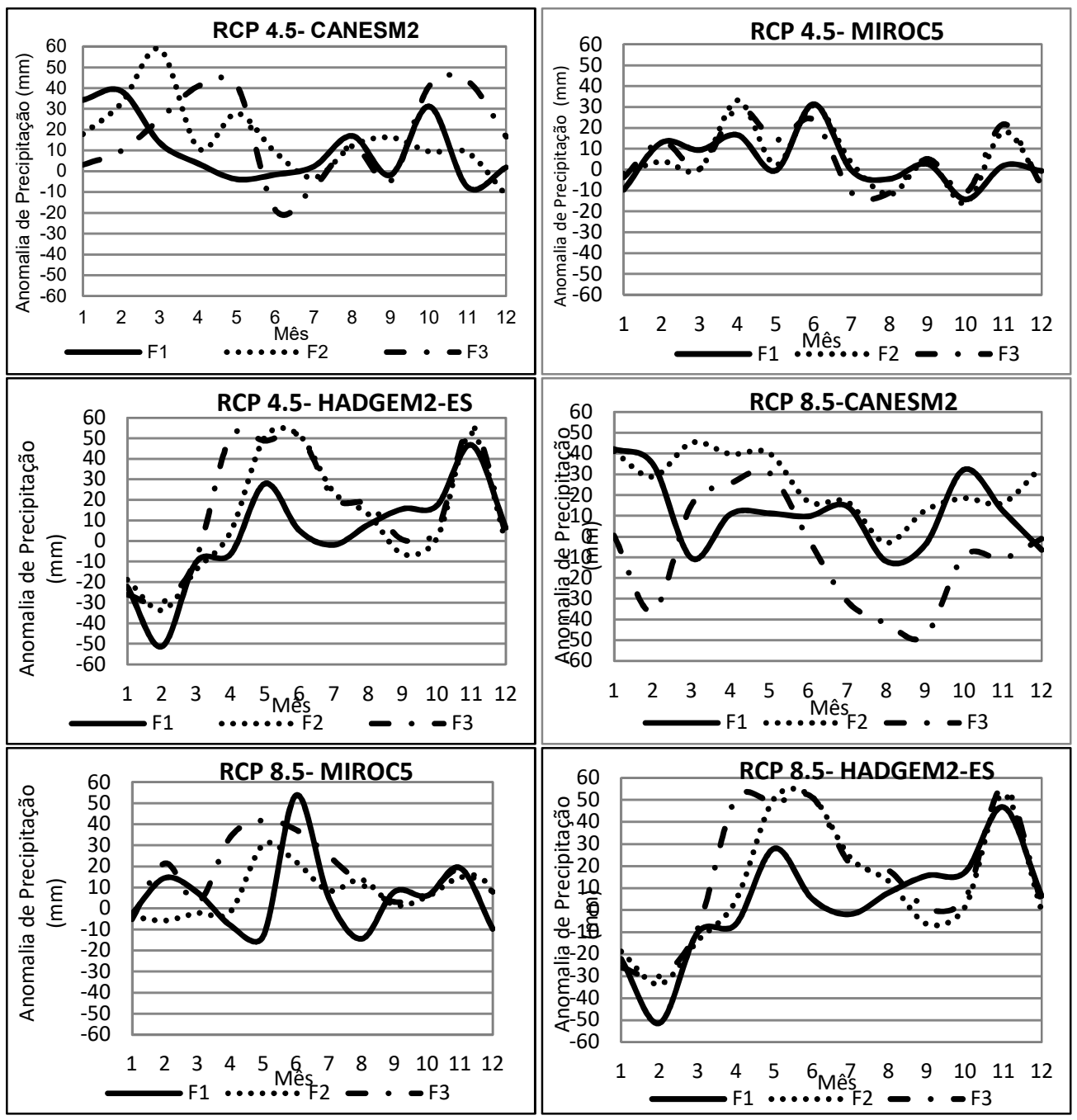

Figura 6: Anomalias de precipitação mensal acumulada projetada pelos MCGs regionalizados pelo modelo ETA para períodos futuros, em Pelotas (RS).

O modelo CANESM2 apontou sua maior anomalia para a precipitação em março para F2, podendo chegar a $40 \mathrm{~mm}$, esse mesmo modelo foi o que mais indicou anomalias negativas, em fevereiro para F3 apontou uma diminuição de $-36,2 \mathrm{~mm}$, ainda para F3 esse modelo indicou uma diminuição para julho de $31,4 \mathrm{~mm}$, agosto de $-41,9 \mathrm{~mm}$ e setembro $-48 \mathrm{~mm}$.

Observando os gráficos das anomalias de temperatura (figura 7) para a projeção RCP 4.5, pode-se notar que o modelo CANESM2 indicou maiores anomalias de aumento de temperatura para os meses de maio, agosto e outubro. Para maio $\mathrm{F} 1$ aponta uma anomalia de $1,3^{\circ} \mathrm{C}$, para $\mathrm{F} 21,8^{\circ} \mathrm{C}$ e para $\mathrm{F} 32,5^{\circ} \mathrm{C}$. Em agosto F1 indica um aumento de $1,5^{\circ} \mathrm{C}, \mathrm{F} 2$ indica um aumento de $2,4^{\circ} \mathrm{C}$ e F3 um aumento de até $2,9^{\circ} \mathrm{C}$. Para outubro F1 mostra um aumento de $1,2^{\circ} \mathrm{C}$, para F2 $1,9^{\circ} \mathrm{C}$ e para F3 $2,5^{\circ} \mathrm{C}$. O modelo MIROC5 indica maiores anomalias para o mês de abril, onde $\mathrm{F} 1$ aponta um aumento de $0,6^{\circ} \mathrm{C}, \mathrm{F} 20,8^{\circ} \mathrm{C}$ e para $\mathrm{F} 31,4^{\circ} \mathrm{C}$, e para junho do F1 mostra um aumento de $1,2^{\circ} \mathrm{C}$, esse aumento não é esperado para F2 e F3 para esse mesmo mês.

O modelo HADGEM2-ES segue uma tendência de aumento entre os futuros, para março, abril, junho, agosto e dezembro. Para março F1 aponta um aumento de $1,1^{\circ} \mathrm{C}$, para $\mathrm{F} 2$ mostra $1,9^{\circ} \mathrm{C}$ de aumento e para $\mathrm{F} 32,6^{\circ} \mathrm{C}$, para o mês de abril F1 aponta anomalia positiva de $1,5^{\circ} \mathrm{C}$, para F2 $1,9^{\circ} \mathrm{C}$ e para F3 $2,1^{\circ} \mathrm{C}$. Para junho, agosto e dezembro foi indicado para $\mathrm{F} 1 \mathrm{um}$ aumento de $1,5^{\circ} \mathrm{C}$, para $\mathrm{F} 22,2^{\circ} \mathrm{C}$, e para $\mathrm{F} 32,3^{\circ} \mathrm{C}$. 


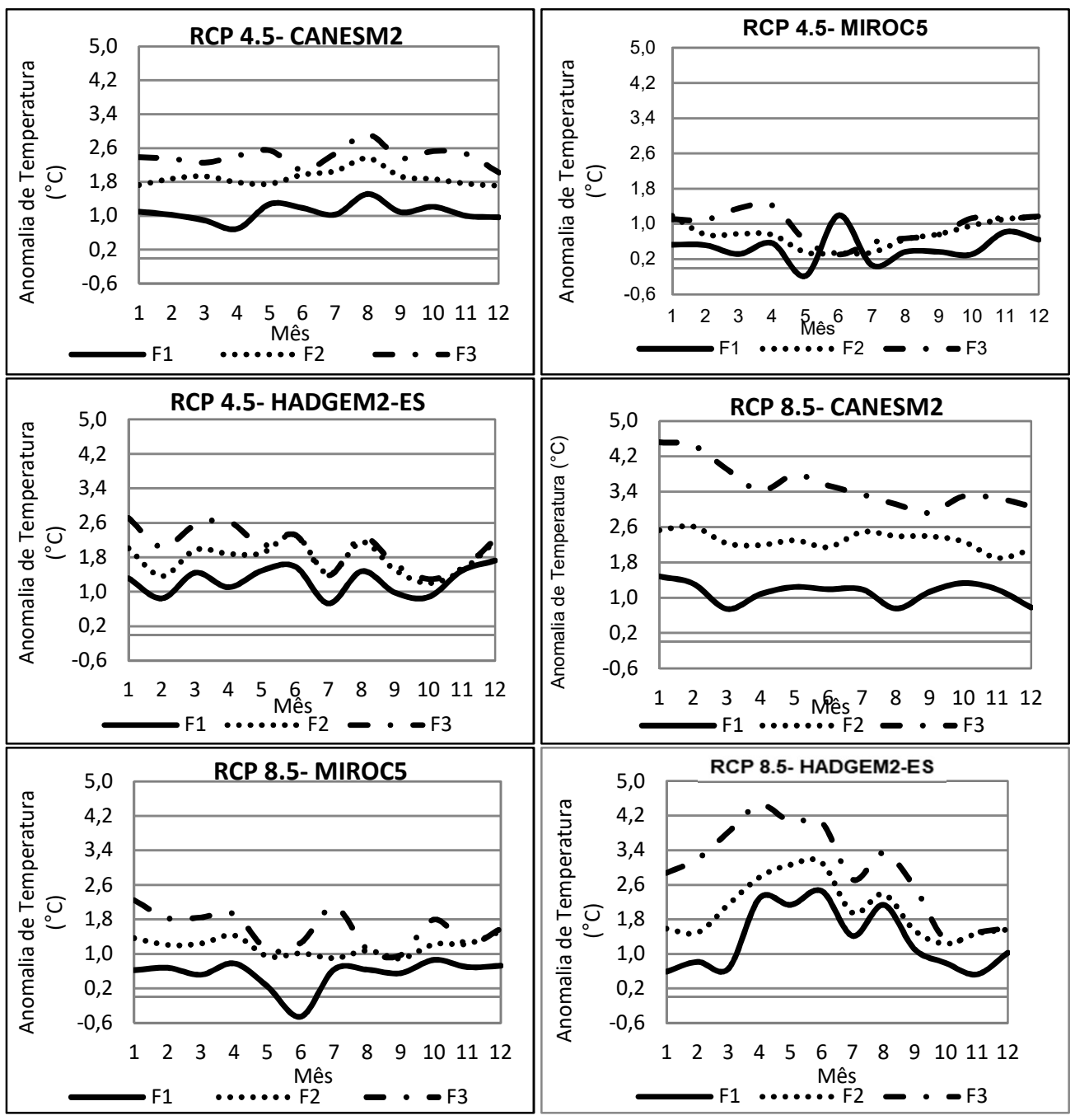

Figura 7: Anomalias de temperatura mensal projetada pelos MCGs regionalizadas pelo modelo ETA, para períodos futuros em Pelotas (RS).

Continuando a análise da figura 7, mas para o cenário RCP 8.5, notou-se um aumento nas anomalias para o modelo CANESM2 para janeiro, onde F1 (2006-2037) indica uma aumento de $1,5^{\circ} \mathrm{C}$, para F2 (20382068) aponta um aumento de $2,5^{\circ} \mathrm{C}$, e para F3 (2039-2099) um acréscimo de até $4,5^{\circ} \mathrm{C}$ na temperatura, e para esse mesmo modelo os meses maio, junho e julho e agosto indicaram para F2 mais de $2^{\circ} \mathrm{C}$ de anomalia e para $\mathrm{F} 3$ mais de $3^{\circ} \mathrm{C}$ de anomalia, podendo em maio do $\mathrm{F} 3$ a temperatura ter um acréscimo de até $3,8^{\circ} \mathrm{C}$. $\mathrm{O}$ modelo MIROC5 aponta para janeiro de $\mathrm{F} 1$ uma anomalia de $0,8^{\circ} \mathrm{C}$, para $\mathrm{F} 21,4^{\circ} \mathrm{C}$ e F3 $1,9^{\circ} \mathrm{C}$.

Para outubro, novembro e dezembro também houveram anomalias de aumento de temperatura, especialmente para F2 e F3. O modelo HADGEM2-ES para abril indica para $\mathrm{F} 1$ anomalia de $2,3^{\circ} \mathrm{C}$, para $\mathrm{F} 2$ $2,8^{\circ} \mathrm{C}$ e para $\mathrm{F} 3$ um aumento de até $4,5^{\circ} \mathrm{C}$, para maio mostra um aumento para $\mathrm{F} 1$ de $2,1^{\circ} \mathrm{C}$, para $\mathrm{F} 2$ um aumento de $3,1^{\circ} \mathrm{C}$ e para $\mathrm{F} 3$ um acréscimo de até $4,1^{\circ} \mathrm{C}$. Em junho $\mathrm{F} 1$ aponta um aumento de $2,5^{\circ} \mathrm{C}$, para $\mathrm{F} 2$ um acréscimo de $3,1^{\circ} \mathrm{C}$ e para $\mathrm{F} 3$ um aumento de até $4^{\circ} \mathrm{C}$.

Pode-se destacar que as anomalias de temperatura indicaram um aumento expressivo principalmente para o final do século (2069-2099). Ressaltando então que para o cenário RCP 4.5, considerado o cenário otimista neste trabalho, o modelo MIROC5, com menores valores de anomalia positiva, indica um aumento médio na temperatura de $0,5{ }^{\circ} \mathrm{C}$ para F1 (2006-2037), enquanto os outros modelos indicam pelo menos $1^{\circ} \mathrm{C}$ de aumento. Esse aumento pode acarretar em vários transtornos, 
principalmente na agricultura onde as culturas são sensíveis a variação climática. Para o RCP 8.5, considerado o cenário pessimista neste estudo, o F3 indica um aumento médio na temperatura de até $3^{\circ} \mathrm{C}$, podendo em alguns meses esse aumento ser maior do que $4^{\circ} \mathrm{C}$. Todas as projeções indicam aumento na temperatura, sendo possível que os invernos se tornem mais quentes em comparação com os verões. As anomalias para o período de F1 (2006-2037) apresentam menores flutuações do que para os períodos subsequentes.

\section{DISCUSSÃO}

Assim como nesta pesquisa, outros estudos apresentaram um aumento de temperatura para Pelotas (RS), no sul do estado, onde a média anual da temperatura aumentou $1,07^{\circ} \mathrm{C}$ nos últimos 50 anos e esse aumento em todo o mundo tem trazido mais chuvas para o Sul, em contraposição, mais seca no Nordeste brasileiro (PILON, 2017). Coerente com esta análise, o estudo de Steinmetz et al. (2007) mostrou para a região de Pelotas/RS, que a temperatura mínima aumentou $1,1^{\circ} \mathrm{C}$ no período $1893-2006$ e $1,8^{\circ} \mathrm{C}$ no período de 1951 2006.

Para todas as variáveis poucas ocorrências de tendências significativas de aumento ou diminuição foram constatadas nas simulações e projeções. Contudo percebe-se que esse resultado corrobora com os trabalhos de Sillmann et al. (2013), onde já se registram menores mudanças nas variáveis brutas de precipitação para a América do Sul. De qualquer maneira se acredita que o aumento de temperatura associado ao aquecimento global e ondas de calor possam promover o aumento da ocorrência de eventos extremos.

A cidade de Pelotas sofre com a grande quantidade de chuvas em certas épocas do ano, tendo como fatores principais, os geográficos, por se localizar em baixa altitude. A falta de planejamento também é um problema, já que a cidade cresceu e a infraestrutura não acompanhou a sua expansão e a drenagem urbana é insuficiente, o que acarreta efeitos negativos para diversos setores, incluindo a economia. A temperatura tem influência direta sobre as culturas produzidas no município, tais como soja, pêssego e arroz. Cultivares de maior necessidade de frio, como o pêssego, tenderão a uma menor produtividade com o aumento da temperatura.

Possivelmente, será necessário refazer o zoneamento periodicamente, considerando dados climáticos mais atuais (WREGE et al., 2007). Mantendo-se a tendência atual de aumento da temperatura mínima no ar, a cultura do arroz irrigado poderá ser beneficiada pela diminuição do risco de frio na fase reprodutiva, mas prejudicada pelo provável decréscimo do potencial de produtividade em Pelotas (RS) (STEINMETZ et al., 2005). Além de impactos sobre a agricultura, alguns eventos extremos que já ocorrem em Pelotas podem ser intensificados, como alagamentos, chuvas torrenciais e inundações.

Apesar disso, não se sabe com que precisão os modelos climáticos podem reproduzir o clima futuro, pois apresentam dificuldades na representação de certas variáveis climáticas naturais e por referir-se a um sistema complexo, no qual há interação de fenômenos diversos, pode exibir certas incertezas. Essas incertezas inerentes aos modelos podem ser atribuídas a diferentes discretizações, parametrizações e modelos de ciclo do carbono (NKOMOZEPI et al., 2012). 
Segundo projeções do IPCC, o aumento das temperaturas médias globais da superfície para F3 em comparação ao período base $1986-2005$ está projetado para os $1,1^{\circ} \mathrm{C}$ a $2,6^{\circ} \mathrm{C}(\mathrm{RCP} 4.5)$ e $2,6^{\circ} \mathrm{C}$ a $4,8^{\circ} \mathrm{C}(\mathrm{RCP}$ 8.5) (IPCC, 2014), o que está de acordo com os resultados encontrados neste trabalho. Nesta pesquisa foram descobertas anomalias positivas de temperatura, havendo aumento principalmente para o final do século. Juntamente com o processo de uso e ocupação dos solos, essas alterações têm sido consideradas como as principais causas de mudanças temporais da precipitação e da vazão (KLIMENT et al., 2011).

Conforme o que foi analisado neste estudo, pode-se perceber uma relação com estudos já realizados para o sudeste da América do Sul, principalmente a região que inclui o extremo sul do Brasil, onde as projeções indicam para o cenário pessimista e para o final do século o aquecimento desta região seria bem maior, possivelmente mais de $3^{\circ} \mathrm{C}$. Existe projeção de aumento da precipitação para o extremo sul do Brasil, mas com maior incremento para RCP 8.5 (15-20\%), o que está de acordo com o que vem sendo observado nas últimas décadas (BERLATO et al., 2017).

Essa pesquisa, para a cidade de Pelotas, indicou para o cenário pessimista que a temperatura pode ter um acréscimo de até $4,5^{\circ} \mathrm{C}$, o que é mais do que o esperado pela literatura para o extremo sul do Brasil, vale ressaltar que esta pesquisa é mais focada em Pelotas e por isso a discrepância com o que foi reportado na literatura.

\section{CONCLUSÕES}

De forma geral, para as projeções anuais, todos os modelos indicaram aumento de temperatura, onde no cenário RCP 4.5 os modelos CANESM2 e HADGEM2-ES indicam uma anomalia de mais de $1^{\circ} \mathrm{C}$ para F1 (2006-2037). Já para o F3 (2069-2099) do cenário RCP 8.5, encontrou-se um aumento de mais de 3,5 $\mathrm{C}$. 0 cenário RCP 4.5 indica para todos os modelos um aumento na precipitação, onde o modelo CANESM2 para F1 (2006-2037) indica uma anomalia de pelo menos 100mm, enquanto para esse mesmo cenário, mas para o F3 (2069-2099), os modelos CANESM2 e HADGEM2-ES indicam um aumento de pelo menos $180 \mathrm{~mm}$.

No cenário RCP 8.5 o modelo CANESM2 para a precipitação do F3 (2069-2099) indicou uma diminuição de mais de $100 \mathrm{~mm}$, enquanto os modelos MIROC5 e HADGEM2-ES para esse mesmo futuro indicam um aumento de pelo menos $200 \mathrm{~mm}$ na precipitação. Desta forma, é possível concluir que Pelotas possa sofrer futuramente tanto com aumento de temperatura como de precipitação anual. Em relação a análise sazonal realizada, pode-se notar que a temperatura também possui uma tendência de aumento, principalmente nos meses de inverno, em relação a precipitação as projeções indicam uma diminuição para o mês de fevereiro e um aumento entre os meses de abril, maio e junho.

O conhecimento resultante dessa pesquisa possibilita que haja ações de planejamento para a cidade de Pelotas, para que auxiliem na melhor adaptação e mitigação dos impactos gerados pelas mudanças climáticas. Algumas medidas como a manutenção dos sistemas de drenagem da cidade e atividades de educação ambiental para a sociedade, se fazem necessário. Tanto o excesso de precipitação quanto a seca, causam impacto na agricultura e torna ações de proteção do solo ainda mais importantes. Todavia, a 
diminuição de emissões de gases do efeito estufa no decorrer dos próximos anos, deve ajudar na perspectiva de reduzir os custos e desafios a serem enfrentados, contribuindo para um desenvolvimento sustentável.

\section{REFERÊNCIAS}

AKBARI, H.; CARTALIS, C.; KOLOKOTSA, D.; MUSCIO, A.; PISELLO, A. L.; ROSSI, F.; SANTAMOURIS, M.; SYNNEF, A.; WONG, N. H.; ZINZI, M.. Local climate change and urban heat island mitigation techniques-the state of the art. Journal of Civil Engineering and Management, v.22, n.1, p.1-16, 2016. DOI:

https://doi.org/10.3846/13923730.2015.1111934

ASADIEH, B.; KRAKAUER, N. Y.. Global trends in extreme precipitation: climate models versus observations. Hydrology and Earth System Sciences, v.19, n.2, p.877-891, 2015. DOI: https://doi.org/10.5194/hess-19-877-2015

ASSENG, S.; EWERT, F.; MARTRE, P.; RÖTTER, R. P.; LOBELL, D. B.; CAMMARANO, D.; KIMBALL, B. A.; OTTMAN, M. J.; WALL, G. W.; WHITE, J. W.; REYNOLDS, M. P.; ALDERMAN, P. D.; PRASAD, P. V. V.; AGGARWAL, P. K; ANOTHAI, J.; BASSO, B.; BIERNATH, C.; CHALLINOR, A. J.; SANCTIS, G.; DOLTRA, J.; FERERES, E.; GARCIA-VILA, M.; GAYLER, S.; HOOGENBOOM, G.; HUNT, L. A.; IZAURRALDE, R. C.; JABLOUN, M.; JONES, C. D.; KERSEBAUM, K. C.; KOEHLER, A. K.; MÜLLER, C.; KUMAR, S. N.; NENDEL, C.; O'LEARY, G.; OLESEN, J. E.; PALOSUO, T.; PRIESACK, E.; REZAEI, E. E.; RUANE, A. C.; SEMENOV, M. A.; SHCHERBAK, I.; STÖCKLE, C.; STRATONOVITCH, P.; STRECK, T.; SUPIT, I.; TAO, F.; THORBURN, P. J.; WAHA, K.; WANG, E.; WALLACH, D.; WOLF, J.; ZHAO, Z. Y. Z.. Rising temperatures reduce global wheat production. Nature Climate Change, v.5, p.143-147, 2015. DOI:

https://doi.org/10.1038/nclimate2470

BACK, A. J.. Aplicação de análise estatística para identificação de tendências climáticas. Pesquisa agropecuária brasileira, v.36, n.5, p.717-726, 2001.

BARCELLOS, C.; LOWE, R.. Expansion of the dengue transmission area in Brazil: the role of climate and cities. Tropical medicine \& international health, v.19, n.2, p.159-168, 2014. DOI: https://doi.org/10.1111/tmi.12227

BARRY, R.; CHORLEY, R.. Atmosfera, Tempo e Clima. 9 ed. Porto Alegre: Bookman, 2013.

BECK, J.. Predicting climate change effects on agriculture from ecological niche modeling: who profits, who loses?. Climatic change, v.116, n.2, p.177-189, 2013. DOI: https://doi.org/10.1007/s10584-012-0481-x

BERLATO, M. A.; CORDEIRO, A. P. A.. Sinais de mudanças climáticas globais e regionais, projeções para o século XXI e as tendências observadas no Rio Grande do Sul: uma revisão. Agrometeoros, v.25, n.2, p.273-302, 2017.

CABRERA, L. C.; COSTA, F. P.; PRIMEL, E. G.. Estimativa de risco de contaminação das águas por pesticidas na região sul do estado do RS. Química Nova, v.31, n.8, p.1982-1986, 2008.

CHOU, S. C.. Modelo regional ETA. Climanálise-Boletim de Monitoramento e Análise Climática, v.1, 1996.

CHOU, S. C.; BUSTAMANTE, J. F.; GOMES, J. L.. Evaluation of Eta Model seasonal precipitation forecasts over South America. Nonlinear Processes in Geophysics, v.12, n.4, p.537-555, 2005.

COSTA, C.; MARQUES, J. R.. Tendência Sazonal das Temperaturas Mínimas e Máximas no Rio Grande do Sul.
In: CONGRESSO BRASILEIRO DE METEOROLOGIA. Anais. Belém: Hangar, 2010.

CRAUFURD, P. Q.; WHEELER, T. R.. Climate change and the flowering time of annual crops. Journal of Experimental Botany, v.60, n.9, p.2529-2539, 2009. DOI: https://doi.org/10.1093/jxb/erp196

GONÇALVES, R. S.. Favelas do Rio de Janeiro: história e direito. Rio de Janeiro: PUC-Rio, 2016.

HANSEN, J.; RUEDY, R.; SATO, M.; LO, K.. Global surface temperature change. Reviews of Geophysics, v.48, p.1-29, 2010. DOI: https://do.org/10.1029/2010RG000345.

IBGE. Instituto Brasileiro de Geografia e Estatística. Censo demográfico: Panorama da cidade de Pelotas/ RS. Rio de Janeiro: IBGE, 2017.

IPCC. Intergovernmental Panel on Climate Change. Cambio climático 2014: Informe de síntesis. Contribución de los Grupos de trabajo I, II y III al Quinto Informe de Evaluación del Grupo Intergubernamental de Expertos sobre el Cambio Climático. Genebra: IPCC, 2014.

IPCC. Intergovernmental Panel on Climate Change. Climate Change 2007: Working Group I: The Physical Science Basis (Summary for Policymakers). Cambridge: IPCC, 2007.

IPCC. Intergovernmental Panel on Climate Change. Summary for Policymakers. Climate Change 2013: The Physical Science Basis. Contribution of Working Group I to the Fifth Assessment Report of the Intergovernmental Panel on Climate Change. Cambridge: Cambridge University Press, 2013.

KANG, Y.; KHAN, S.; MA, X.. Climate change impacts on crop yield, crop water productivity and food security: a review. Progress in Natural Science, v.19, n.12, p.1665-1674, 2009. DOI: https://doi.org/10.1016/i.pnsc.2009.08.001

KLIMENT, Z.; MATOUŠKOVÁ, M.; LEDVINKA, O.; KRÁLOVEC, V.. Trend analysis of rainfall-runoff regimes in selected headwater areas of the Czech Republic. Journal of Hydrology and Hydromechanics, v.59, n.1, p.36-50, 2011.

LOBELL, D. B.; SCHLENKER, W.; COSTA-ROBERTS, J.. Climate trends and global crop production since 1980 . Science, v.333, n.6042, p.616-620, 2011. DOI: https://doi.org/10.1126/science.1204531

MARENGO, J. A.; CAMARGO, C. C.. Surface air temperature trends in Southern Brazil for 1960-2002. International Journal of Climatology: a Journal of the Royal Meteorological Society, v.28, n.7, p.893-904, 2008. DOI: https://doi.org/10.1002/joc.1584

MORAES, J. M.; PELLEGRINO, G.; BALLESTER, M. V.; MARTINELLI, L. A.; VICTORIA, R. L.. Estudo preliminar da evolução temporal dos componentes do ciclo hidrológico da bacia do Rio Piracicaba. In: SIMPÓSIO BRASILEIRO DE RECURSOS HÍDRICOS, 11. Anais. Recife: ABRH, p.27-32, 2015.

MOSS, R. H.; EDMONDS, J. A.; HIBBARD, K. A.; MANNING, M. R.; ROSE, S. K.; VUUREN, D. P.; CARTER, T. R.; EMORI, S.; KAINUMA, M.; KRAM, T.; MEEHL, G. A.; MITCHELL, J. 
F.; NAKICENOVIC, N.; RIAHI, K.; SMITH, S. J.; STOUFFER, R. J.; THOMSON, A. M.; WEYANT, J. P.; WILBANKS, T. J.. The next generation of scenarios for climate change research and assessment. Nature, v.463, n.7282, p.747, 2010. DOI: https://doi.org/10.1038/nature08823

NKOMOZEPI, T.; CHUNG, S.. Assessing the trends and uncertainty of maize net irrigation water requirement estimated from climate change projections for Zimbabwe. Agricultural Water Management, v.111, p.60-67, 2012. DOI: https://doi.org/10.1016/j.agwat.2012.05.004

NOBRE, C. A.; MARENGO, J. A.. Mudanças Climáticas em rede: um olhar multidisciplinar. Bauru: Canal 6, 2017

PILON, A. A.. Agroamigo e território: a evolução do programa de microcrédito rural orientado no estado do Rio Grande do Norte entre os anos de 2005 e 2014. Dissertação (Mestrado em Economia) - Universidade Federal do Rio Grande do Norte, Natal, 2017.

PILOTTO, I. L.; CHOU, S. C.; NOBRE, P.. Seasonal climate hindcasts with Eta model nested in CPTEC coupled oceanatmosphere general circulation model. Theoretical and applied climatology, v.110, n.3, p.437-456, 2012. DOI: https://doi.org/10.1007/s00704-012-0633-y

RAMIREZ-VILLEGAS, J.; CHALLINOR, A.. Assessing relevant climate data for agricultural applications. Agricultural and forest meteorology, v.161, p.26-45, 2012. DOI: https://doi.org/10.1016/j.agrformet.2012.03.015

RANJITKAR, S.; SUJAKHU, N. M.; MERZ, J.; KINDT, R.; XU J.; MATIN, M. A.; ALI, M.; ZOMER, R. J.. Suitability analysis and projected climate change impact on banana and coffee production zones in Nepal. PloS one, v.11, n.9, 2016. DOI: https://doi.org/10.1371/journal.pone.0163916

RESENDE, N.; CHOU, S. C.. Influência das condições do solo na climatologia da previsão sazonal do modelo ETA. Revista Brasileira de Climatologia, v.15, p.64-79, 2015. DOI: http://dx.doi.org/10.5380/abclima.v15i0.37366

ROSE, G.; OSBORNE, T.; GREATREX, H.; WHEELER, T.. Impact of progressive global warming on the global-scale yield of maize and soybean. Climatic change, v.134, n.3, p.417-428, 2016. DOI: https://doi.org/10.1007/s10584-016-1601-9

SCHNEIDEMESSER, E.; MONKS, P. S.; ALLAN, J. D.; BRUHWILER, L.; FORSTER, P.; FOWLER, D.; LAUER, A.; MORGAN, W. T.; PAASONEN, P.; RIGHI, M.; SINDELAROVA K.; SUTTON, M. A.. Chemistry and the linkages between air quality and climate change. Chemical Reviews, v.115, n.10, p.3856-3897, 2015

DOI: http://doi.org/10.1021/acs.chemrev.5b00089

SELUCHI, M. E.; CHOU, S. C.. Synoptic patterns associated with landslide events in the Serra do Mar, Brazil. Theoretical and Applied Climatology, v.98, n.1-2, p.67-77, 2009. DOI: https://doi.org/10.1007/s00704-008-0101-x
SELUCHI, M. E.; NORTE, F. A.; SATYAMURTY, P.; CHOU, S. C. Analysis of three situations of the foehn effect over the Andes (zonda wind) using the Eta-CPTEC regional model. Weather and forecasting, v.18, n.3, p.481-501, 2003. DOI: https://doi.org/10.1175/15200434(2003)18\%3C481:AOTSOT\%3E2.0.CO;2

SILLMANN, J.; KHARIN, V. V.; ZWIERS, F. W.; ZHANG, X.; BRONAUGH, D.. Climate extremes indices in the CMIP5 multimodel ensemble: Part 2: Future climate projections. Journal of Geophysical Research: Atmospheres, v.118, n.6, p.2473-2493, 2013. DOI: https://doi.org/10.1002/jgrd.50188

SIQUEIRA, V. A.; COLLISCHONN, W.; FAN, F. M.; CHOU, S. C.. Previsão de cheias por conjunto a partir de previsões operacionais do EPS regional Eta na bacia do TaquariAntas/RS. Revista Brasileira de Recursos Humanos, v.21, n.3, p.587-602, 2016. DOI: http://doi.org/10.1590/2318$\underline{0331.011616004}$

SOUZA, W. M.; AZEVEDO, P. V.. Avaliação de tendências das temperaturas em Recife-PE: mudanças climáticas ou variabilidade?. Engenharia Ambiental: Pesquisa e Tecnologia, v.6, n.3, 2009.

SRIVASTAV, R. K.; SCHARDONG, A.; SIMONOVIC, S. P.. Computerized tool for the Development of Intensity: Duration Frequency Curves under a Changing Climate. Water Resources Research Report. Technical manual, v.1, 2015.

STEINMETZ, S.; SIQUEIRA, O. D.; WREGE, M. S.; HERTER, F. G.; REISSER JÚNIOR, C.. Aumento da temperatura mínima do ar na região de Pelotas, sua relação com o aquecimento global e possíveis consequências para o arroz irrigado no Rio Grande do Sul. In: CONGRESSO BRASILEIRO DE AGROMETEOROLOGIA. Anais. Campinas: SBAgro, 2005.

STEINMETZ, S.; WREGE, M. S.; HERTER, F. G.; REISSER JUNIOR, C.. Influência do aquecimento global sobre as temperaturas máximas, mínimas e médias anuais na Região de Pelotas, RS. In: CONGRESSO BRASILEIRO DE AGROMETEOROLOGIA. Anais. Aracaju: SBAgro, 2007.

VIEIRA, R. M. G.; DERECZYNSKI, C. P.; CHOU, S. C.; GOMES, J. L.; PAIVA NETO, A. C. Avaliação das Previsões de Precipitação do Modelo Eta para Bacia do Rio São Francisco em Minas Gerais, Brasil. Anuário do Instituto de Geociências, v.38, n.2, p.15-23, 2015. DOI: http://doi.org/10.11137/2015 21523

WREGE, M. S.; HERTER, F. G.; STEINMETZ, S.; REISSER JUNIOR, C.; GARRASTAZU, M. C.; CARAMORI, P. H.; MATZENAUER, R.; BRAGA, H. J.. Influência do aquecimento global sobre a fruticultura de clima temperado na região Sul do Brasil diante de alguns cenários de mudanças climáticas. In: CONGRESSO BRASILEIRO DE AGROMETEOROLOGIA. Anais. Aracaju: SBAgro, 2007.

A CBPC - Companhia Brasileira de Produção Científica (CNPJ: 11.221.422/0001-03) detém os direitos materiais desta publicação. Os direitos referem-se à publicação do trabalho em qualquer parte do mundo, incluindo os direitos às renovações, expansões e disseminações da contribuição, bem como outros direitos subsidiários. Todos os trabalhos publicados eletronicamente poderão posteriormente ser publicados em coletâneas impressas sob coordenação da Sustenere Publishing, da Companhia Brasileira de Produção Científica e seus parceiros autorizados. Os (as) autores (as) preservam os direitos autorais, mas não têm permissão para a publicação da contribuição em outro meio, impresso ou digital, em português ou em tradução. 